\title{
Maternal risk factors associated with intrauterine growth restriction: hospital based study
}

\author{
Ashwani N ${ }^{1}$, Neela Aruna Rekha ${ }^{2}$, Babu M.S ${ }^{3}$, C. Suresh Kumar ${ }^{4}$, O. Tejo Pratap ${ }^{5}$ \\ ${ }^{1}$ Dr. Neetika Ashwani, Medical Officer, Special newborn care unit (SNCU), ${ }^{2}$ Dr. Neela Aruna Rekha, Assistant \\ Professor, Gynaecology and Obstetrics, ${ }^{3}$ Dr. Mendu Suresh Babu, Assistant Professor, Department of Paediatrics, \\ ${ }^{4}$ Dr. C. Suresh Kumar, HOD and Professor of Neonatology, all authors are affiliated with Niloufer Hospital, Osmania \\ Medical College, Hyderabad, ${ }^{5}$ Dr. O. Tejo Pratap, Neonatologist, Department of Neonatology, Fernandez Hospital, \\ Hyderguda, Hyderabad, India.
}

Address for Correspondence: Dr. Neetika Ashwani, Email: cuteniti_19@yahoo.com

\begin{abstract}
Objective: To study the maternal risk factors of intrauterine growth restriction. Methods: A retrospective analysis was done at a tertiary care Hospital. Ninety three inborn intrauterine growth restriction cases were selected and data was collected by perusal of antenatal records. Intrauterine growth restriction was defined as occurring if birth weight of the newborn is below 10th percentile for gestational age on the intrauterine growth curve based on Fenton's charts. Results: Mean age of the mothers included in the study was $20.2 \pm 2.857$ years. Forty four $(47.3 \%)$ were born to primipara and 49 $(52.7 \%)$ to multigravida. Younger maternal age, multiparity were found to be the significant socio-demographic factors associated with Intrauterine growth restriction while, pre eclampsia, chronic hypertension and anemia were the maternal biological factors found to be significantly associated on bivariate analysis. Conclusions: Younger age, multigravida and chronic medical illnesses are the main risk factors in this hospital based population. Inclusion of prenatal education and screening for medical disorders in antenatal care guidelines will help in curtailing the incidence of IUGR.
\end{abstract}

Keywords: maternal factors, IUGR, tertiary centre

\section{Introduction}

Linear growth failure is caused by multiple factors including parental factors. Infants with intrauterine growth restriction (IUGR) are defined as those with birth weight below the $10^{\text {th }}$ percentile for its gestational age and it is a consequence of several factors [1]. Genetic and environmental factors influence the development throughout the growth period. Linear growth failure is largely confined to the intrauterine period and the first few years of life, and it is caused by multiple factors like inadequate diets, infections, maternal chronic diseases etc. [2,3].

IUGR is observed in about $24 \%$ of newborns; approximately 30 million infants suffer from IUGR every year [4]. The burden of IUGR is concentrated mainly in developing countries, especially in Asia

Manuscript received $14^{\text {th }}$ September 2016

Reviewed: $25^{\text {th }}$ September 2016

Author Corrected: $7^{\text {th }}$ October 2016

Accepted for Publication $19^{\text {th }}$ October 2016 which accounts for nearly $75 \%$ of all affected infants. In India, the prevalence of LBW has been reported as $26 \%$ [5] while the proportion of IUGR has been found to be $54 \%$ [6,7]. The neonatal mortality rate of a small for gestational age infant born at 38 weeks is $1 \%$ compared to $0.2 \%$ in those appropriate for gestational age [8].

The common risk factors include maternal causes (hypertension, diabetes, cardiopulmonary disease, anemia, malnutrition, smoking, drug use), fetal causes (genetic disease including aneuploidy, congenital malformations, fetal infection, multiple pregnancies), and placental causes (placental insufficiency, placental infarction, placental mosaicism). The risk factors for IUGR different in our region compared to developed region. IUGR increases the risk for intrapartum asphyxia, preterm delivery, and risks associated with preterm delivery, including but not limited to respiratory distress syndrome, sepsis, seizures, 
intraventricular hemorrhage, and necrotizing enterocolitis $[9,10]$. Other neonatal morbidities include polycythemia, hyperbilirubinemia, hypoglycemia, and hypothermia. Effects of IUGR often affect childhood and adult life, as well. During the childhood period, associations are noted for increased risk of cerebral palsy, growth delay, short stature, and neurodevelopmental impairment [9,11]. In adult life, individuals who had IUGR were noted to have higher incidence of hypertension, diabetes, obesity, coronary artery disease, stroke, and metabolic syndrome [12].

However in developing countries evidence on the association between these factors and IUGR is scarce. Hence we tried to elucidate some of the major risk factors for intrauterine growth restriction in south India.

\section{Materials and Methods}

A retrospective descriptive analysis was undertaken at a tertiary care hospital, Niloufer Hospital, Hyderabad, India to study the maternal determinants of intrauterine growth restriction.
Retrospectively babies born in the 8 months period from October 2015 to May 2016 were included in the study. We included infants born to singleton mothers with birth weight below $10^{\text {th }}$ centile on Fenton charts in our hospital. We excluded infants with major malformations.

Antenatal records of mothers were scrutinized for maternal and obstetric factors, which included age, parity, maternal weight, hemoglobin level, spacing between present and past pregnancy, pregnancy induced hypertension, antenatal visits and h/o abortion/stillbirth, any illness and treatment received during pregnancy and record of hospitalization during present pregnancy. Weight of the newborns was obtained from case records. In our hospital, baby is weighed immediately after birth and information is noted on the mothers ' case sheet. Data was analyzed using $\mathrm{R}$ programming software version 3.0. For descriptive statistics frequencies were tabulated and chi square test was done to see significance between the groups. A ' $\mathrm{P}$ ' value $<0.05$ was considered statistically significant.

\section{Results}

A total of 4315 babies were delivered in our center during the study period, of which $93(2.15 \%)$ with mean birth weight of $1.93 \pm 0.36 \mathrm{~kg}$ (range $0.89-2.3 \mathrm{~kg}$ ) and mean gestation age of $38.19 \pm 1.75$ weeks (range $32-41$ weeks) were diagnosed as IUGR. Forty four were born to primipara $(47.3 \%)$ and $49(52.7 \%)$ to multigravida. Fifty eight $(62.4 \%)$ were females and $35(37.6 \%)$ were males. Forty three $(46.2 \%)$ mothers were at young age $(<20 \mathrm{yrs})$ and eight $(8.6 \%)$ mothers with weight $<45 \mathrm{~kg}$. Birth spacing less than 1 year were found in $13(14 \%)$ women and $22(23.7 \%)$ women were found to have birth spacing between 1-2 years.

The etiological factors are shown in table 1.

Table 1: Perinatal risk factors.

\begin{tabular}{|c|c|c|c|}
\hline & SGA $^{\#}$ & OVERALL $^{\#}$ & p value \\
\hline Anemia & 10.8 & 1.96 & $<0.001$ \\
Hypertension & 10.8 & 2.94 & $<0.001$ \\
Pre eclampsia & 16.1 & 5.02 & $<0.001$ \\
Eclampsia & 1.1 & 0.50 & 0.957 \\
Diabetes mellitus & 1.1 & 0.60 & 0.999 \\
APH $^{*}$ & 8.6 & 1.04 & 0.001 \\
Infections $^{\text {Hypothyroid }}$ & 1.1 & 0.69 & 0.999 \\
No med comp $^{* *}$ & 4.3 & 4.77 & 0.999 \\
\hline
\end{tabular}

Note: ${ }^{\#}$ - denotes percentage, ${ }^{*}$ - Antepartum hemorrhage, $*^{*}$ - No medical complications

Pre eclampsia was considered as one of the important risk factors of IUGR babies followed by anemia, hypertension and antepartum hemorrhage. The other perinatal risk factors did not reach statistical significance. 
In forty three $(46.2 \%)$ babies, no medical cause was found for SGA babies. Hence we analyzed socio-demographic factors for these SGA babies (table 2).

Table-2: Socio-demographic factors with no medical complications.

\begin{tabular}{|c|c|c|}
\hline & Frequency $(\mathbf{n}=\mathbf{4 3})$ & Percentage $(\mathbf{\%})$ \\
\hline young maternal age & 17 & 39.5 \\
\hline low maternal weight & 3 & 7.0 \\
\hline Multigravida & 10 & 23.3 \\
\hline short stature & 1 & 2.3 \\
\hline Undetermined & 12 & 27.9 \\
\hline
\end{tabular}

Young maternal age had high prevalence (39.5\%) for SGA babies followed by multigravida (23.3\%), low maternal weight $(7.0 \%)$ and short stature $(2.3 \%)$.

Twelve $(27.9 \%)$ babies born to primi mothers had no cause determined. Of 12 babies 7 were associated with oligohydramnios.

\section{Discussion}

The ability to reach an optimal birth weight, results from the interaction between the fetal growth potential and the environment. The fetus requires several substrates for normal growth, the most important being oxygen, glucose and amino acids. Any persistent decrease in the availability of any of these substrates will limit the ability of the fetus to reach its growth potential. The availability of substrates necessary for fetal growth may be limited by pathological conditions affecting the mother, the placenta and the fetus [13].

IUGR is a multifactorial phenomenon. Many of these factors are inter-related and they can confound the results in addition to modifying the independent estimates of relative risk associated with a risk factor [14]. The perinatal risk factors responsible for IUGR in developing countries differ from the western world. Unlike our country the common risk factors related to IUGR in western countries is smoking.

In this retrospective study, we described risk factors for severe IUGR. Obstetric and maternal risk factors for IUGR are well described in many studies and the present cohort is comparable to cohorts described in other studies.

Our study demonstrated that pre eclampsia, hypertension, and anemia were the main maternal biological factors associated with IUGR which was comparable with other studies [13]. Anemia is a common problem in developing countries in pregnant women and increases the incidence of LBW and IUGR $[15,16]$.
Maternal age and parity were found to be the significant maternal socio-demographic determinants of intrauterine growth restriction in the present study. Teenage mothers (age less than 20 years) are well known for adverse pregnancy outcomes. However, in this study teenage mothers were independently associated with IUGR compared to middle and older age mothers which are comparable to other studies [1719]. This result is in contrast to other studies in India. Instead of teenage mothers, studies in India associated maternal weight and primiparity $[15,16]$.

Kramer's meta-analysis [20], and other studies conducted in developing countries have identified maternal weight $(<45 \mathrm{~kg})$, maternal height $(<145 \mathrm{~cm})$ as potential risk factors for LBW babies. Low socioeconomic status and low educational status leads to low health consciousness, lower nutritional status and low antenatal attendance, leading to the increased risk of IUGR babies [21]. A short interpregnancy interval is associated with IUGR [22]. In the present study, previous history of abortion/stillbirth, spacing, maternal weight, and antenatal visits were not found to be significant. Another study done in India showed that toxemia of pregnancy $(30.09 \%)$, hypertensive diseases of pregnancy (HDP) excluding toxemia (5.8\%), diabetes mellitus $(1.94 \%)$, medical disorders including renal and cardiac $(3.88 \%)$, anemia and Intra Uterine infection $(0.97 \%)$ were the main conditions responsible for LBW and in $56.3 \%$ pregnancies, no cause could be ascertained [13]. But our study showed that $16.1 \%$ mothers suffered from pre eclampsia, $10.8 \%$ of the mothers with IUGR were anaemic and $46.2 \%$ of them 
were young maternal age. Around $10.8 \%$ of the mothers with IUGR babies suffered from hypertension.

We found 12 cases $(27.9 \%)$ had no cause determined. Of late genetic factors affecting the mother, placental and fetus are increasingly reported. Genetic causes can contribute to 5-20\% of IUGR, especially for early onset growth restricted fetuses. Monitoring of weight gain on prenatal visit can identify the maternal nutrition. Also, measurement of the symphysis-fundal height (SFH) height provides a helpful measure to assess fetal growth during office visits.

The women at risk for IUGR can be assessed with uterine artery Doppler to further evaluate the initiation of baby ASA before 16 weeks gestation. Diagnosis of IUGR is made by when the ultrasound EFW is less than 10th percentile. The umbilical artery Doppler should be performed in IUGR fetuses to formulate the antenatal management plans. Invasive testing should be offered to rule out aneuploidy and in utero fetal infection. Serial growth ultrasound and UA Doppler studies are used to follow-up the fetus (es) with IUGR. As the IUGR foetuses have fivefold increase in the stillbirth rate as well as threefold increase in neonatal mortality and morbidity, a very close monitoring of the labour is warranted. As the chance of IUGR babies in subsequent pregnancies is higher, these patients should be followed up post-nataly.

This study provides baseline information from a tertiary hospital in this region, which could help with possible intervention regarding maternal and newborn health in the future. We could not take more information on certain risk factors like weight gain during pregnancy because of lack of available data from the records. We recommend the health authorities to strengthen the maternal health programmes focusing on maternal nutrition and iron and folic acid supplementation during antenatal period.

The strategy also needs to focus attention on nutrition education to facilitate better weight gain during adolescent period. Discouraging teenage pregnancy is also essential in order to reduce the burden of LBW/IUGR babies.

Thus findings of this study emphasizes the need for improving the quality and utilization of antenatal care, nutritional education to improve the weight gain during pregnancy, spacing, and prevention and proper management of risk factors like anemia and hypertension. The researchers concluded that there is a need to control risk factors to reduce the incidence and prevalence of Intra uterine growth restriction.

\section{Conclusions}

IUGR newborns are common in the developing countries. So in conclusion, comprehensive approaches which institute a combination of interventions to improve the overall health of the women are needed. Such approaches are likely to be most effective in reducing the IUGR problem in India. As IUGR infants can have long term morbidities, authorities should concentrate on measures to reduce this problem.

Acknowledgement- We thank Dr. Raja Sriswan Mamidi, Scientist B, National Institute of Nutrition, Hyderabad for assistance with statistical analysis and for comments that greatly improved the manuscript.

Funding: Nil, Conflict of interest: None initiated, Permission from IRB: Yes

\section{References}

1. Gluckman PD, Pinal CS. Regulation of fetal growth by the somatotrophic axis. J Nutr. 2003 May; 133 (5 Suppl 2): 1741S-1746S.

2. Shrimpton R, Victora CG, de Onis M, Lima RC, Blossner M, Clugston G. Worldwide timing of growth faltering: implications for nutritional interventions. Pediatrics. 2001 May;107(5):E75.

3. Xue F, Willett WC, Rosner BA, Forman MR, Michels KB. Parental characteristics as predictors of birthweight. Hum Reprod. 2008 Jan;23(1):168-77. Epub 2007 Oct 12.

4. de Onis M, Blossner M, Villar J: Levels and patterns of intrauterine growth retardation in developing countries. Eur J Clin Nutr. 1998 Jan; 52 Suppl 1:S5-15.

5. Director General World Health Organization: Bridging the gaps. The World Health Report 1995. Available from url http://www.who.int/whr/ 1995/en/ whr 95_en.pdf

6. Antonisamy B, Sivaram M, Richard J, Rao PS. Trends in intra-uterine growth of single live births in southern india. J Trop Pediatr. 1996 Dec;42(6):339-41. 
7. Pinheiro A, David A, Joseph B. Pregnancy weight gain and its correlation to birth weight. Indian $\mathrm{J}$ Med Sci. 2001 May;55(5):266-70.

8. Jaafari RM, Ahwaz UMS. Intrauterine growth restriction. Available from url http://220.128.112.10/ftp/ medical. Accessed on 16-08-2011.

9. von Beckerath AK, Kollmann M, Rotky-Fast C, Karpf E, Lang U, Klaritsch P. Perinatal complications and long-term neurodevelopmental outcome of infants with intrauterine growth restriction. Am J Obstet Gynecol. 2013 Feb;208(2):130.e1-6. doi: 10.1016/j. ajog. 2012. 11.014. Epub 2012 Nov 15.

10. Bernstein IM, Horbar JD, Badger GJ, Ohlsson A, Golan A. Morbidity and mortality among very-lowbirth-weight neonates with intrauterine growth restriction. The Vermont Oxford Network. Am J Obstet Gynecol. 2000 Jan;182(1 Pt 1):198-206.

11. Pallotto EK, Kilbride HW. Perinatal outcome and later implications of intrauterine growth restriction. Clin Obstet Gynecol. 2006 Jun;49(2):257-69.

12. Barker DJ. Adult consequences of fetal growth restriction. Clin Obstet Gynecol. 2006 Jun; 49 (2): 270-83.

13. Narang A, Chaudhuri MK, Kumar P. Small for gestational age babies: Indian Scene. Indian J Pediatr. 1997 Mar-Apr;64(2):221-4.

14. Singh G, Chouhan R, Sidhu K. Maternal factors for low birth weight babies. Medical J Armed Forces India.2009 Jan;65(1):10-2. doi: 10.1016/S0377-1237 (09)80045-2. Epub 2011 Jul 21.
15. Mavlankar DV, Gray RH, Trivedi CR. Risk factors for preterm and term low birthweight in Ahmedabad, India. Int J Epidemiol. 1992 Apr;21(2):263-72.

16. Acharya D, Nagraj K, Nair NS, Bhat HV. Maternal Determinants of Intrauterine Growth Retardation: A Case Control Study in Udupi District, Karnataka. Ind J Commun Med 2004 Oct-Dec;29(4):181-2.

17. Lee KS, Ferguson RM, Corpuz M, Gartner LM. Maternal age and incidence of low birth weight at term: a population study. Am J Obstet Gynecol. 1988 Jan; 158(1):84-9.

18. Aldous MB, Edmonson MB. Maternal age at first childbirth and risk of low birth weight and preterm delivery in Washington State. JAMA. 1993 Dec 1;270 (21):2574-7.

19. Strobino DM, Ensminger ME, Kim YJ, Nanda J. Mechanisms for maternal age differences in birth weight. Am J Epidemiol. 1995 Sep 1;142(5):504-14.

20. Kramer MS. Determinants of low birth weight: methodological assessment and meta-analysis. Bull World Health Organ. 1987;65(5):663-737.

21. Ferraz EM, Gray RH, Cunha TM. Determinants of preterm delivery and intrauterine growth retardation in north-east Brazil. Int J Epidemiol.1990Mar;19(1): 101-8.

22. Zhu BP, Rolfs RT, Nangle BE, Horan JM. Effect of the interval between pregnancies on perinatal outcomes. N Engl J Med. 1999 Feb 25;340(8): 589-94.

\section{How to cite this article?}

Ashwani N, Neela Aruna Rekha, Babu M.S, C. Suresh Kumar, O. Tejo Pratap. Maternal risk factors associated with intrauterine growth restriction: hospital based study. Int J Med Res Rev 2016;4(12):2125-2129.doi:10.17511/ijmrr. 2016.i12.08. 